\title{
TONANTZIN, COATLICUE E A VIRGEM DE GUADALUPE. DA CONTINUIDADE HÍBRIDA À RESISTÊNCIA NA LUTA DAS MULHERES CHICANAS
}

\author{
Fernando Torres Londoño* \\ Manuela Ribeiro Cirigliano**
}

\section{RESUMO}

Neste artigo, abordamos a Virgem de Guadalupe na condição de símbolo espiritual, como a chamou Gloria Anzaldúa. Iniciamos na mariologia que formatou o princípio constituinte do feminino na cultura náuatle, a deusa Coatlicue em Guadalupe. Partindo do culto de substituição imposto no Tepeyac, serão considerados os recursos presentes na invenção da devoção até a difusão do relato canônico das aparições. Depois, seguimos a feminista chicana Gloria Anzaldúa em sua vivência da fronteira física entre México e EUA e da fronteira simbólica do universo chicano e abordamos a ressignificação rebelde feita pelas lutas das chicanas que têm feito da Guadalupe uma virgem guerreira, ecoando autoras e artistas plásticas contemporâneas.

Palavras-chave: Virgem de Guadalupe; mulheres chicanas; Coatlicue; Tonantzin; resistência.

\section{TONANTZIN, COATLICUE AND THE VIRGIN OF GUADALUPE. FROM HYBRID CONTINUITY TO RESISTANCE IN THE FIGHT OF CHICANA WOMEN}

\section{ABSTRACT}

In this article, we approach the Virgin of Guadalupe as a spiritual symbol, as designated by Gloria Anzaldúa. We start in the mariology that shaped the constitutive principle of the feminine in Nahuatl culture, Coatlicue into Guadalupe. Starting from the replacement

* Doutor em História pela USP. Professor dos Programas de Pós-Graduação em História e Ciência da Religião da PUC-SP.

** Bacharela em Filosofia (UNISUL) e mestra em Ciência da Religião (PUC-SP). Membra do GREPO (PUC-SP). 
cult imposed on Tepeyac, will be considered the resources present in the invention of devotion until the dissemination of the canonical reports of the apparitions. Then we follow the Chicana feminist Gloria Anzaldúa in her experience of the physical border between Mexico and USA and the symbolic border of the chicano universe and approach the rebellious resignification made by the chicanas, that have made of Guadalupe a virgin warrior, echoing contemporary authors and visual artists.

Keywords: Virgin of Guadalupe; Chicana women; Coatlicue; Tonantzin; resistance.

\section{TONANTZIN, COATLICUE Y LA VIRGEN DE GUADALUPE. DE LA CONTINUIDAD HÍBRIDA A LA RESISTENCIA DE LAS LUCHAS DE LAS MUJERES CHICANAS}

\section{RESUMEN}

En este artículo, abordamos a la Virgen de Guadalupe como un símbolo espiritual, como la llamó la feminista chicana Gloria Anzaldúa. Empezamos en la mariología que formó el principio constitutivo de lo femenino en la cultura náhuatl, Coatlicue en Guadalupe. A partir del culto de substitución impuesto en el Tepeyac, se considerarán los recursos presentes en la invención de la devoción hasta que se difunda el relato canónico de las apariciones. Luego seguimos a Anzaldúa en su experiencia de las fronteras física (México-EUA) y simbólica (universo chicano) y nos acercamos de la resignificación rebelde hecha por las luchas de las chicanas que han hecho de Guadalupe una virgen guerrera, de que se apropian autoras contemporáneas y artistas visuales.

Palabras claves: Virgen de Guadalupe; mujeres chicanas; Coatlicue; Tonantzin; resistencia

Com Maria José Fontelas Rosado Nunes, homenageada neste número da Mandrágora, aprendemos que, devido à invisibilidade a que as mulheres são submetidas ou à naturalidade com que se lhes ignora, devemos sempre nos perguntar: onde estão as mulheres? Que papel elas ocupam no estabelecimento de cada sociedade em termos de relações sociais e de relações entre os gêneros e a religião? O que também apreendemos com a professora Maria José é que, quando se trata de estudar o catolicismo, cuja história é protagonizada e, em grande parte, escrita por homens, há 
que se perguntar pelos longos silêncios sobre as mulheres e pela origem e interesses por trás dos estigmas sobre o feminino.

Neste artigo, interrogamos um silêncio sobre mulheres, ou melhor, um silêncio sobre deusas, procurando trazer os traços e as manifestações presentes nas apropriações que foram feitas por mulheres e homens que buscavam evitar o apagamento do passado, da religião antiga e dos sentidos antigos. Ao mesmo tempo, apontamos para as rupturas dos silêncios produzidos desde a fronteira, desde o indistinto, trazendo outras vozes e outros gritos de resistência, como os da feminista chicana Gloria Anzaldúa. Finalmente, colocaremos as apropriações recentes que as chicanas têm feito a partir do feminismo dessas deusas silenciadas e apagadas pelo patriarcado e pelo cristianismo.

Idealizado para homenagear a nossa querida Zeca, nos propomos neste texto escrito a quatros mãos - de uma mulher e de um homem, uma filósofa feminista e um historiador - a realizar um desafiador diálogo em que nos debruçamos sobre silêncios, continuidades, apropriações e ressignificações.

\section{$* * *$}

\section{INTRODUÇÃO}

A história do catolicismo no México, no Brasil e na América Latina foi constituída por muitas operações que formataram o cristianismo às necessidades da implantação da Igreja como instituição que controlava a sociedade, os homens e as mulheres e os corpos desses homens e mulheres. Na prática, o catolicismo americano foi muito diferente do modelo imaginado por missionários, bispos reformadores e autoridades eclesiásticas.

Por sua parte, a instituição eclesiástica defendeu constantemente a legitimidade religiosa e até divina de muitas de suas ações, estabelecendo modelos de comportamentos e virtudes. Além do âmbito da teologia e da administração dos sacramentos, a Igreja afirmou modelos de virtude a serem seguidos pelos fiéis através de seu grande leque de devoções. Ao mesmo tempo, no entanto, houve persistência das religiões indígenas e africanas, além da independência que homens e 
mulheres demonstraram frente às imposições de práticas morais e aos poderes da Igreja com seus subterfúgios, camuflagens e resistências.

Este nosso artigo a quatro mãos pretende ser, com todos os seus riscos, nosso primeiro ensaio de aproximação a diferentes tentativas de desconstrução dos discursos presentes na invenção híbrida da Virgem de Guadalupe, tocando num leque de silêncios normalmente não tratados em relação à devoção guadalupana. Ao mesmo tempo, ao dialogar com a experiência de resistência das mulheres chicanas que leem Guadalupe pelo avesso, desde a rebeldia, queremos evidenciar, no tempo denso do mito, a ressignificação da deusa que apontava para o conflito e para o paradoxo da criação e da destruição e da vida e da morte, evocando, para tanto, a figura da deusa Coatlicue.

Entendemos que a devoção à Virgem de Guadalupe passa pela formatação das divindades femininas mesoamericanas associadas à criação, à fertilidade e à maternidade feita a partir da mariologia católica nos séculos XVI e XVII. Tal formatação, realizada no âmbito da sujeição da população nativa com a legitimidade que trouxe o catolicismo, permitiu o desenvolvimento de uma devoção caraterizada pela submissão, em particular das mulheres, para as quais a Virgem de Guadalupe era apresentada como modelo. Na contramão desta domesticação, desde as margens e à fronteira, feministas chicanas como Gloria Anzaldúa apontaram para o significado rebelde que as mulheres chicanas têm conferido à devoção de Guadalupe, referindo as raízes indígenas da devoção e o lado silenciado pela narrativa católica.

Inicialmente, introduziremos a origem da devoção, suas raízes indígenas e a permanência de parte destes componentes na devoção desenvolvida no XVI e cristalizada no discurso eclesiástico no século XVII. Depois, a partir da consideração de Guadalupe como a vigência de um arquétipo que resgata a ancestralidade indígena na psique de mulheres latinas, caminharemos pelas jornadas de reconexão das feministas chicanas com sua espiritualidade/sacralidade através da reconstituição de Guadalupe.

\section{O TEPEYAC, TONANTZIN E COATLICUE}

A ênfase de ser Guadalupe mais uma advocação mariana como muitas outras - desta vez, produzida no solo americano - tem primado 
tanto entre a erudição eclesiástica que se configurou em relação a ela como em parte da devoção popular desde que se publicou o primeiro texto que estabelecia uma narrativa canônica para as aparições da Virgem de Guadalupe em 1648. Maria teria aparecido no Tepeyac em 1531, de forma extraordinária e inédita, para estabelecer o triunfo do cristianismo e introduzir os povos nativos no caminho da salvação cristã trazida pela conquista. Adotamos aqui uma posição contrária, que enfatiza a apresentação das origens mexicanas da devoção, fazendo também referência a uma leitura feminista desde a fronteira e apontando assim para continuidades, permanências e ressignificações.

Entre as várias continuidades que podem ser estabelecidas entre a devoção à Virgem de Guadalupe e o passado pré-hispânico está o monte Tepeyac, onde se encontra a igreja (de fato, tem sido várias) que abriga a imagem da santa desde a metade do século XVI. Na cultura nauatle, o monte (tepetl) estava associado à chuva, aos deuses, ao germinar da vida e à fertilidade (Miguel LEÓN-PORTILLA, 2001) e outros montes também estavam presentes em narrativas de origem, como o Coatepec - onde teria nascido Huitzilopochtli, uma das divindades supremas mexicanas - e alguns deles eram considerados deuses, como Temilco, Popocatepetl, Iztaccihuatl (Adela FERNANDEZ, 2008).

Nos códices pré-hispânicos, existia um ícone composto por uma espécie de saco, com um nó na parte de cima, normalmente associado a montes com histórias cósmicas, lugares de sinais ou revelações divinas, enquanto nas esculturas de pedra ou em cerâmicas de divindades, eram colocadas saias que faziam referência a encostas e montanhas. Nos casos em que aconteciam essas associações entre divindades e montes, algumas estruturas e altares para culto ou veneração denominados de teocalli (casa da divindade) eram erguidas em seus topos, onde oferendas eram colocadas e rituais eram realizados nos tempos apropriados (Adela FERNANDEZ, 2008). Isso acontecia em vários dos montes que rodeavam a cidade de México-Tenochtitlan, sendo um deles o Tepeyac, onde existia um teocalli para honrar a Tonantzin.

Frei Bernardino de Sahagún, escrevendo por volta de 1576, informou em seu primeiro livro, História General de las Cosas de la Nueva España, que a expressão Tonántzin queria dizer nuestra madre (nossa 
mãe) em nauatle. Designava-se, assim, uma deusa considerada a mãe dos deuses, coração da terra e que seria nuestra abuela (nossa avó). Sahagún diz que a expressão era utilizada para se referir à deusa Cihuacóatl, que, segundo ele, "quer dizer mulher da cobra" (Bernardino de SAHAGÚN, 1989, p. 33, tradução nossa).

Apesar de Cihuacóatl ser uma divindade criadora e geradora associada à terra, Sahagún não associou diretamente a ela a sua condição de ter parido a humanidade e Ihe ter multiplicado. Em náuatle, cihuatl significa mulher, abrangendo um grande campo feminino associado à irmã maior e à mãe e "parece juntar-se a outros elementos - o milho, o sustento, a cobra, as estrelas - para expressar distintos conceitos e explicar distintas ações naturais ou humanas" (Eduardo N. do SANTOS, 2002, p. 236). Sahagún só atribuiu um caráter negativo à deusa Cihuacóa$t l$, dizendo que trazia adversidades como pobreza, abatimento, trabalho e aflição e que aparecia à noite gritando e assustando as pessoas e que, por isso, a ela se faziam festas e oferendas para que não os ofendesse (Bernardino de SAHAGÚN, 1989).

Sahagún deu conta da origem dos deuses segundo os mexicanos no livro III, que começou com a história de Huitzilopochtli e repetiu em grande parte a narrativa presente em outros cronistas do século XVI. Contou que próximo à cidade de Tula, na serra de Coatépec, vivia uma mulher chamada Coatlicue, que era mãe dos Centzonhuitznahua (Los Cuatrocientos Surianos) e de uma filha que se chamava Coyolxauhqui. A mulher, que ali fazia penitência, estava um dia varrendo e sentiu que um bolinho de penas caia sobre ela: o pegou e o guardou no seu seio, mas depois, quando o quis encontrar, não o achou. Coatlicue, com outras figuras femininas associados ao divino na Mesoamérica, ficou grávida, suscitando a raiva dos seus filhos que, sentindo-se desonrados, planejaram matar a mãe sob o comando da irmã. Apavorada, Coatlicue foi consolada pelo seu filho Huitzilopochtli, que desde o ventre lhe falou que não temesse, pois ele a protegeria. Quando a mãe estava para ser morta, Huitzilopochtli nasceu já adulto e armado. Assim, enfrentou e venceu a seus irmãos e matou Coyolxauhqui, lhe decepando a cabeça e rolando seu corpo ladeira abaixo, despedaçando-o (Bernardino de SAHAGUN, 1989).

\footnotetext{
"quiere decir mujer de la culebra".
} 
Sabemos hoje que Sahagún, ao se referir a Tonantzin, Cihuacóatl e Coatlicue, estava apontando para um conceito divino feminino personificado por atributos ou atavios que faziam referência à criação e à maternidade, presente em diversas divindades e sob várias formulações e nominações. Coatlicue ou A de Saia de Serpentes, tem sido associada pelos/as estudiosos/as atuais a outras deidades femininas com variações nas denominações e nos diversos registros:

Cinteotl (Deusa do Milho), Tonacacihuatls ou Omecihuatl (Senhora de Nossa Carne, Senhora Dois), Xochiquetzal (Flor Preciosa), Teteoinan (Mãe dos Deuses), Tlazolteotl (Devoradora de Inmundices), Tlaelcuani (Senhora da Guerra) Yaocihuatl ou Itzpapalotl (Mariposa de Obsidiana), Tlatecuhtli (Senhora da Terra ou Monstro da Terra), Mictecacihuatl (Senhora do Inframundo) e Tonantzin (Nossa Mãe) (Eduardo N. do SANTOS, 2002, p. 236).

Como veremos mais para frente, Sahagún também apontaria de, forma indireta, para o apagamento ou silenciamento de uma das dimensões constitutivas do entendimento do mundo entre os mexicanos: a dualidade. Isto se revela no monólito de Coatlicue que está no museu Nacional de Antropologia do México e é descrito da forma a seguir por Adela Fernandez:

No monólito mais representativo dessa divindade, nós a vemos com uma saia de cobras, um atributo relacionado ao terrestre e humano em termos de sabedoria, e o constante movimento da vida, decadência e morte, mudança de pele ou forma e folhagem, movimento sinuoso do que rasteja e transforma; seios caídos da mãe que cuidou de inúmeros deuses; colar de mãos e corações que representam a criação, sua qualidade como Tlaliyolo, "coração da terra" cujos movimentos destroem, e o in ollin in yolotl, "movimento do coração", ou seja, emoção humana, carne e sangue, força, comida dos deuses; no cinto preso com um crânio humano provido de olhos, ele mostra sua eterna vigília de onde prevalece seu domínio sobre a vida e a morte; os ornamentos de tira de couro vermelho encimados por caracóis são símbolos de múltiplas matrizes que representam suas gestações contínuas; garras nos pés e nas mãos enfatizam as forças brutais da natureza e a ferocidade implacável da própria deusa. Ela 
é maternal e assassina, feroz e nobre² (Adela FERNANDEZ, 2008, p. 109, tradução nossa).

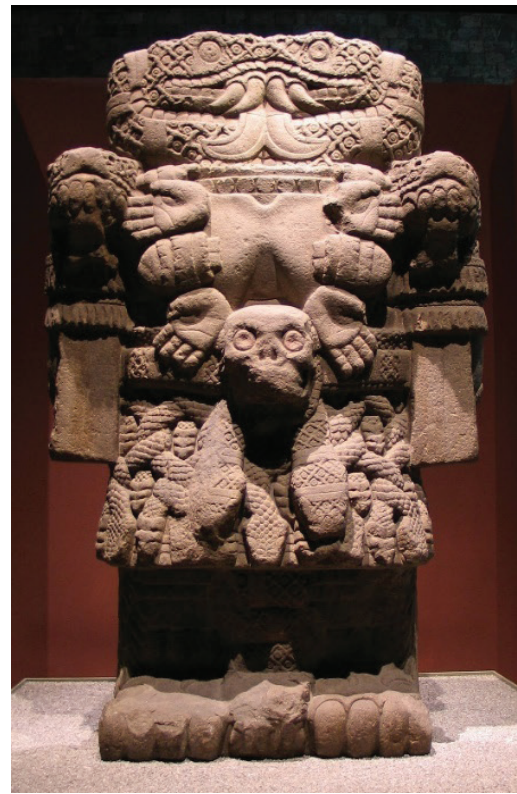

\section{Figura 1: Estátua de Coatlicue exposta no Museu Nacional de Antropologia na Cidade do México}

Luidger/CC BY-SA (http://creativecommons.org/licenses/by-sa/3.0/)/Domínio público. ${ }^{3}$

2 En el monolito mas representativo de esta deidad, la vemos con una falda de serpientes, atributo relacionado con lo terreno y los humano en cuanto a sabiduría se refiere, y al constante movimiento de la vida, decadencia y muerte, cambio de piel o de forma y follaje, movimiento sinuoso de lo que repta y se transforma; senos flácidos de la madre que ha amantado a innumerables dioses; collar de manos y corazones que representan la creación, su calidad de Tlaliyolo, 'corazon de la tierra' cuyos movimientos destruyen, y el in ollin in yolotl, "movimiento del corazón", o sea la emoción humana, carne y sangre, fuerza, alimento de los dioses; en el cinturón abrochado con un cráneo humano provisto de ojos, muestra su eterna vigilia desde donde prevalece su dominio sobre la vida y la muerte; los adornos de tira de cuero rojo rematados por caracoles, son símbolos de múltiples matrices que representan sus continuas gestaciones; las garras en pies y manos enfatizan las brutales fuerzas de la naturaleza y la ferocidad implacable de la misma diosa. Es maternal y asesina, feroz y noble.

3 Agradecemos a gentil colaboração de Sharley Cunha na localização das imagens e respectivas fontes. 
Por reunir todos estes princípios e elementos em antagonismo, Coatlicue seria a deidade mais complexa do universo náuatle, sintetizando, ao mesmo tempo, o celeste, o terrenal e inframundo, a vida e a morte. "Dualidade da vida, uma síntese da dualidade e uma terceira perspectiva - algo além do que uma mera dualidade ou uma síntese da dualidade" 4 , como explica Gloria Anzaldúa (1987, p. 46, tradução nossa), uma das autoras que citaremos na segunda parte do artigo e que também dialoga com a arte contemporânea.

\section{UM PINTOR INDÍGENA E UMA IMAGEM PARA O TEPEYAC}

Depois de 1528, os franciscanos, que começavam a chegar de forma expressiva ao México - chamado agora de Nueva España - colaboraram com a destruição de pirâmides e templos da religião antiga, substituindo muitos deles por construções católicas como ermidas, capelas, igrejas, conventos - feitas muitas vezes com as mesmas pedras das edificações destruídas. Isto também foi feito nos montes próximos à Cidade do México, entre eles o Tepeyac, onde estava o teocalli, a mãe dos deuses nomeada de Tonantzin, que passou a ter uma ermida direcionada à devoção de Hernán Cortés e de vários de seus soldados, que reverenciavam uma invocação mariana de Extremadura, a Virgem de Guadalupe.

A população indígena da região e de outras regiões continuou a trazer oferendas ao local. Simpático a esse culto mariano que aparecia vizinho à cidade do México, o bispo Alfonso de Montufar teria mandado confeccionar uma Imaculada Conceição para colocar na ermida. Acredita-se que o bispo encomendou a imagem a uma oficina de pintura estabelecida pelos franciscanos onde, sob a supervisão de frades, pintores indígenas ajudavam a pintar imagens para as igrejas, capelas e conventos que se estavam construindo ${ }^{5}$.

Coube a Marcos, um pintor indígena conhecido através da documentação apurada por Edmundo O'Gorman, a quem aqui seguimos,

[... ] duality in life, a systhesis of duality, and a third perspective - something more than mere duality or a systhesis of duality.

5 Para a reconstituição do que seriam esses primórdios da devoção à virgem de Guadalupe, ver: Edmundo O'Gorman, Desterro de Sombras. México: UNAM, 1991. 
realizar a imagem para o Tepeyac ${ }^{6}$ (Edmundo O'GORMAN, 1991, p. 246). Pintou, ele, uma jovem indígena, de pele morena, cabelo preto solto - como cabia iconograficamente em termos mexicanos a uma moça solteira - que encarnava a Maria recebendo a visita do anjo Gabriel, representando assim a Anunciação. Enfatizou a discrição e o recato de sua condição virginal e a santidade que a rodeava nos traços suaves do rosto, nos olhos semifechados e nas mãos juntas em posição de oração. Cobriu sua cabeça com um manto turquesa pontuado de estrelas que envolvia também o seu corpo e a colocou em pé, moldurada por uma rocalha e sustentada por um anjo acima de uma almofada, seguindo, provavelmente, os modelos presentes em estampas vindas da Alemanha

Talvez o fato de que a encomenda era destinada a uma capela de índios fez com que o pintor, mesmo seguindo os modelos vindos da Europa, tenha adaptado as imagens de Maria para seus devotos indígenas, tomando uma adolescente inconfundivelmente nativa da terra para representar a Virgem Maria. Talvez esta não tenha sido a primeira vez que isto aconteceu, o que pode ser constatado pelos muitos anjos pintados e esculpidos com claros traços indígenas na América do século XVI.

A imagem, por sua vez, deve ter sido de agrado do bispo, que mandou colocar o quadro na ermida. Não restam registros de sua introdução ali, mas soube-se, sim, de alguns detalhes da sua origem e da recepção que obteve através de um incidente relatado por O'Gorman: em 1556, ficou registrada uma polêmica pública na Información, que dava conta de uma acusação do provincial dos franciscanos contra o bispo. Em um sermão, o primeiro acusou o segundo de estar incentivando a devoção a uma imagem miraculosa que estava atraindo os indígenas à ermida, mas que não passaria de "uma pintura que feita por Marcos, índio pintor” (Edmundo O'GORMAN, 1991, p. 246). A polêmica não foi para frente e a devoção continuou crescendo e atraindo a população indígena e não indígena do lugar.

6 No debate que se trava no México com relação a virgem de Guadalupe, entre "aparicionistas e anti-apariconistas", respeitando a devoção popular, nos colocamos como autores do lado da análise social e da literatura acadêmica compreendendo a devoção desde seu contexto social e cultural tanto de formação como de permanência. Acreditamos que nossa reflexão acrescenta aspectos que ampliam sua compreensão para o estudo dos significados e usos da devoção a Guadalupe entre as mulheres de México, chicanas e América Latina. 


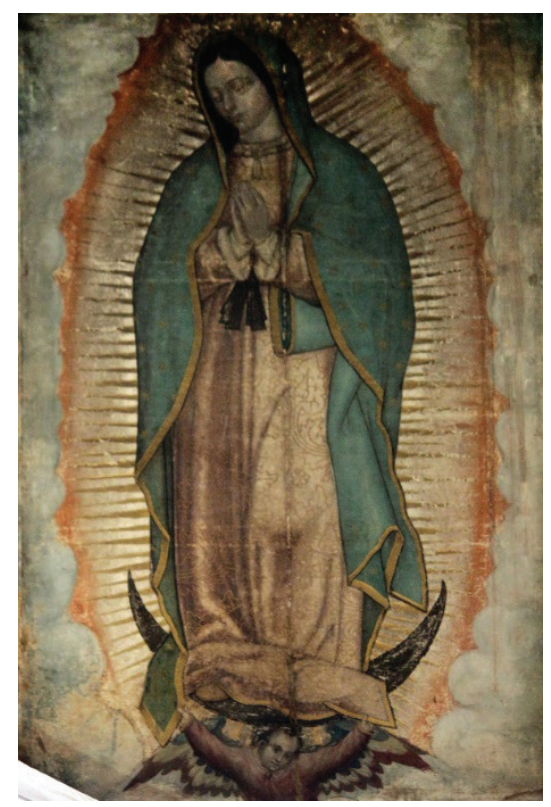

Figura 2: Nossa Senhora de Guadalupe

Autor desconhecido (1531, por Juan Diego)/Domínio Público

Porém, a um observador conhecedor das crenças indígenas como Sahagún, não escapou a quem era, de fato, que os índios estavam cultuando ali. Por volta de 1576, em um apêndice de sua obra chamada de Adição sobre Superstições (Adición sobre supersticiones), incluiu entre os diversos lugares onde ainda se mantinham idolatrias antigas

[...] uma pequena colina chamada Tepeácac e os espanhóis chamam de Tepeaquilla, e agora é chamada Nuestra Señora de Guadalupe; neste lugar eles tinham um templo dedicado à mãe dos deuses que chamavam Tonantzin, o que significa nossa mãe (Bernardino de SAHAGÚN, 1989, p. 704, tradução nossa).

Segundo Sahagún, ali vinham pessoas de muitas regiões, homens e mulheres, jovens e velhos, que traziam oferendas, realizavam sacrifícios

[... ] un montencillo que se llama Tepeácac y los españoles llaman de Tepeaquilla, y ahora se llama Nuestra Señora de Guadalupe; en este lugar tenian um templo dedicado a la madre de los dioses que llamaban de Tonantzin, que quiere decir nuestra madre. 
e faziam festas muito concorridas em honra dessa deusa. Acrescenta, ainda, que

[...] agora que a Igreja de Nossa Senhora de Guadalupe está construída lá, eles também a chamam Tonantzin. Onde este fundamento deste Tonantzin nasceu não se sabe ao certo, mas sabemos de fato que a palavra significa desde sua primeira imposição até o antigo Tonantzin, e é algo que deve ser remediado porque o próprio nome da mãe de Deus é Nossa Senhora e não é Tonantzin ${ }^{8}$ (Bernardino de SAHAGÚN, 1989, p. 705, tradução nossa).

Para o cronista franciscano, essa identificação entre Tonantzin e Nossa Senhora era uma "invención satânica" para ocultar a idolatria existente debaixo dessa invocação e que era de causar suspeitas que, existindo tantas igrejas de "Nossa Senhora, e eles não vão a elas, e vêm de terras distantes para este Tonantzin, como no passado"9 (Bernardino de SAHAGUN, 1989, p. 706, tradução nossa).

Sahagún constatou o crescimento de um culto de advocação de Guadalupe onde estariam conjuntamente Tonantzin e Nossa Senhora em seu apêndice sobre as superstições (Supersticiones). Essa identidade que chocou a Sahagún, representada primeiro pela capela que substituiu o teocalli e depois pela imagem ali colocada, contou com a aceitação dos devotos indígenas que teriam contribuído com a narrativa de milagres e graças feitas por esta que seguia sendo mãe de homens e mulheres, mas com outra forma de nomeação. Elementos da prática antiga, como as oferendas, teriam permanecido no culto do século XVI (e alguns chegam até hoje) enquanto outros de origem católica, como as narrativas de milagres juntaram-se nessa identificação. Assim, a devoção foi sendo elaborada pelos devotos indígenas, mestiços e nascidos na terra, como referente a Tepeyac e claramente diferente da devoção da Virgem de Guadalupe do Santuário de Extremadura em Es-

$8 \quad[.$.$] y ahora que esta allí edificada la Iglesia de Nuestra Señora de Guadalupe también la llaman$ Tonantzin. De donde haya nacido esta fundación de esta Tonantzin no se sabe de cierto, pero esto sabemos de cierto que el vocablo significa de su primera imposición a aquella Tonantzin antigua, y es cosa que se debía remediar porque el propio nombre de la madre de Dios Señora Nuestra no es Tonantzin.

9 Nuestra Señora, y no van a ellas, y vienen de lejas tierras a esta Tonantzin, como antiguamente. 
panha, que tinha vindo com Hernán Cortés e os outros conquistadores provenientes dessa região.

\section{O RELATO INDÍGENA E AS APARIÇOES DA VIRGEM NO TEPEYAC}

Passados 92 anos da colocação da imagem no Tepeyac, quando o culto à virgem de Guadalupe ali venerada já tinha uma identidade com a cidade de México, foi publicado o livro Imagem da Virgem Maria, Mãe de Deus de Guadalupe, apareceu milagrosamente na Cidade do México. Celebrado em sua história, com a profecia do décimo segundo capítulo do Apocalipse, de autoria de Miguel Sanchez ${ }^{10}$ (David BRADING, 2002). O livro foi publicado no ano de 1648 por Miguel Sanchez (1594-1674), que era padre, tinha o título acadêmico de bacharel e era conhecido na Cidade do México por seus inflamados e eruditos sermões. Como outros padres que virão a escrever posteriormente sobre a virgem de Guadalupe, Sanchez era criollo, palavra que identificava descendentes de espanhóis de várias gerações atrás e que se afirmava socialmente identificando-se com a "terra do México".

A obra, de retórica inflamada e carregada, apresentava um exercício de mariologia criolla através de um volume expressivo de textos bíblicos - em particular o capítulo 12 do Apocalipse. Nele, Sanchez estabeleceu uma identidade "profética" entre a "mulher do Apocalipse", Maria Mãe de Deus, Nossa Senhora de Guadalupe e a imagem cultuada na igreja do Tepeyac, que "milagrosamente" teria aparecido no México e se mantinha presente no poncho de Juan Diego.

O texto teve grande repercussão entre a elite eclesiástica da cidade e incentivou o vigário da Igreja do Tepeyac, o também criollo Luis Laso de la Vega, a publicar em nauatle, Huei Tlamahuiçoltica no ano seguinte, 1649. Traduzido como O Grande Acontecimento, o livro fazia uma apresentação da devoção, narrava as aparições da virgem e listava 14 milagres mantidos pela "tradição" (David BRADING, 2002, p. 137). A parte de maior repercussão começa com a expressão Nican Mopohua, que em nauatle significa algo como "Aqui se conta e narra as aparições

10 Imagen de la Virgen Maria, Madre de Dios de Guadalupe, milagrosamente aparecida en la ciudad de México. Celebrada en su historia, con la profecia del capítulo doce del Apocalipsis, de autoria de Miguel Sanchez. 
da virgem no Tepeyac ao índio Juan Diego, no advento de 1531". A narrativa das aparições foi traduzida logo pelo próprio Laso de la Vega, obtendo grande reconhecimento por parte da hierarquia eclesiástica e expressiva difusão por parte dos devotos. A partir dali, se transformou no relato canônico da devoção, sendo seguido, glosado, interpretado, profusamente ilustrado e considerado, no âmbito eclesiástico e devocional, como registro histórico da devoção (David BRADING, 2002, p. 148).

O relato das 4 aparições da virgem no monte do Tepeyac ao índio Juan Diego começa com "Aqui se conta, em ordem, como há pouco tempo apareceu maravilhosamente a sempre Virgem Santa Maria, Mãe de Deus, nossa rainha, no Tepeyac, que se chama Guadalupe (Paulo SUESS, 1992, p. 476. ) $)^{11 "}$. A corrente de identidade entre a virgem e o lugar ficou estabelecida nos nomes e títulos colocados, que serão repetidos pedagogicamente no texto em outros momentos. A seguir, há um resumo de claro uso retórico, do que seria relatado: "Primeiro se deixou ver a um índio pobre, chamado Juan Diego; depois sua preciosa imagem apareceu diante do novo bispo Dom Frei Juan de Zumarraga. Também se narram todas as maravilhas que foram feitas" (Paulo SUESS, 1992, p. 476).

A frase "depois sua preciosa imagem" antecipa o final do relato, quando, ante o bispo e testemunhas, "desenhou-se no manto e apareceu a preciosa imagem da sempre Virgem Maria, mãe de Deus, da forma como está e se guarda ainda hoje no seu templo de Tepeyac que se chama Guadalupe" (Paulo SUESS, 1992, p. 476). Manifesta-se ali o objetivo do relato de estabelecer a identidade entre a Virgem Maria, Mãe de Deus, que teria aparecido por 4 vezes a Juan Diego, também nomeada no texto como "Senhora do Céu" e a imagem que se guardava na igreja do Tepeyac, que não teria sido pintada por mão humana, mas desenhada miraculosamente pela própria virgem.

A narrativa das quatro aparições da virgem no Tepeyac, além da aparição extraordinária no poncho de Juan Diego, recuperou e expressou em um drama de sentido hierofânico, o que a população indígena do lugar estava fazendo desde quando a ermida foi levantada no lugar

Adotamos aqui a poética tradução em português presente em: SUESS, Paulo. A Conquista Espiritual Petrópolis, Vozes, 1992. 
do teocalli a Tonantzin e ganhou o nome de Guadalupe: afirmar a continuidade da veneração a mãe da humanidade através de uma advocação mariana, um processo que, na sua interpretação, não escapou à determinação de Sahagún de desvelar idolatrias em práticas cristãs.

Esse processo de interculturalidade e de produção de uma nova realidade de procedência híbrida reforçou-se com a virgem morena pintada pelo índio Marcos, de clara apropriação nativa do ícone mariano e terminou encontrando em Antônio Valeriano - assistente bilíngue de Sahagún, que foi postulado como o indígena autor do relato original na metade do XVI - um intérprete em condições de fazer um relato em nauatle absolutamente pontuado de referências às divindades mexicanas da criação, da fertilidade e da maternidade (LEÓN-PORTILLA, Miguel, 2001, p. 52).

Mesmo com as alterações do marianismo que se constituía no México e que apagaram a dualidade integradora da Coatlicue na unilateralidade de Guadalupe - que como "mãe do verdadeiro Deus" se sobrepôs à "mãe dos Deuses" - a Tonantzin, que tinha seu teocalli no Tepeyac, manteve-se em nova "advocação" através da Senhora do Céu, que teria aparecido a Juan Diego, por quatro vezes, no mesmo lugar onde as deusas da vida e da morte eram cultuadas.

\section{UMA GUADALUPE CHICANA}

A constituição do povo mexicano foi perpassada pelo conflito, conforme nos conta Gloria Anzaldúa (1987):

No início do século XVI, os espanhóis e Hernán Cortés invadiram e conquistaram o México com a ajuda de tribos que os astecas haviam subjugado. Antes da conquista, existiam 25 milhões de indígenas no México e em Yucatán. Logo após a conquista, a população indígena era inferior a 7 milhões. Em 1650, apenas 1,5 milhão de indígenas de sangue puro restavam. Os mestizos, que eram geneticamente equipados para sobreviver à varíola, sarampo e tifo (doenças do Velho Mundo para as quais os nativos não tinham imunidade) fundaram uma nova raça híbrida e herdaram a América do Sul e Central. Én 1521 nacío uma nueva raza, el mestizo, el mexicano (pessoas de sangue 
indígena e espanhol), uma raça que nunca havia existido ${ }^{12} / 13$ (Gloria ANZALDÚA, 1987, p. 5, tradução nossa).

Nos séculos seguintes, o atual sul dos Estados Unidos, à época território mexicano, foi paulatinamente invadido por norte-americanos, resultando em sangrentos conflitos que culminaram no Tratado de Guadalupe-Hidalgo. Este tratado, que leva o nome da cidade onde foi assinado em 1848, selou a anexação de parte do território do Texas, Novo México, Arizona, Colorado e Califórnia pelos Estados Unidos e com ela, a perda do pertencimento cultural pelos chicanos - a população mexicana ali residente - independentemente de sua cidadania estadunidense:

Gringos do sudoeste dos Estados Unidos consideram os habitantes das fronteiras como transgressores, estrangeiros - não importa se são chicanos, indígenas ou negros. Não entre, invasores serão estuprados, mutilados, estrangulados, gaseados, baleados. O único habitante "legítimo" são aqueles no poder, os brancos e aqueles que se alinham a eles. A tensão pressiona os habitantes da fronteira como vírus. Ambivalência e desassossego vivem ali e a morte não é uma estranha ${ }^{14}$ (Gloria ANZALDÚA, 1987, p. 3-4, tradução nossa).

12 At the beginning of the 16th century, the Spaniards and Hernán Cortés invaded Mexico and, with the help of tribes that Aztecs had subjugated, conquered it. Before the Conquest, there were twenty-five million Indian people in Mexicos and the Yucatán. Immediately after the Conquest, the Indian population had been reduced to under seven million. By 1650 , only one-and-a-half-million pure-blooded Indians remained. The mestizos who were genetically equipped to survive small pox measles, and typhus (Old World diseases to which the natives had no immunity), founded a new hybrid race and inherited Central and South America. Én 1521 nacío uma nueva raza, el mestizo, el mexicano (people of mixed Indian and Spanish blood), a race that had never existed before.

13 Como simbolismo da vida em fronteira, Anzaldúa produz este texto com uma língua própria, o Spanglish, em que mescla as variações do inglês e o espanhol com que convive. Buscando conservar essa marca linguística da autora, não serão traduzidas as palavras em espanhol das citações de Anzaldúa, a exemplo da tradução de seu poema To live in Borderlands means you publicada no n. 16, v. 16 da Mandrágora (ANZALDÚA, 2010).

14 Gringos in the U.S. Southwest consider the inhabitants of the borderlands transgressor, aliens - whether they possess documents or not, whether they're Chicanos, Indians or Blacks. Do not enter, trespassers will be raped, maimed, strangled, gassed, shot. The only "legitimate" inhabitants are those in power, the whites and those who align themselves with whites. Tension grips the inhabitants of the borderlands like a virus. Ambivalence and unrest reside there and death is no stranger. 
Esse tensionamento levou à configuração do movimento identitário chicano na década de 1960. Sua proposta gira em torno de três ideias principais: o recuerdo, o descubrimiento e a voluntad, conceitos que inspiravam ações coletivas com o propósito de delineamento de uma nova identidade a partir do resgate da cultura mexicana. Inicialmente caracterizado pelo engajamento coletivo, o chicanismo passa a ganhar, nas décadas de 1970-1980, algumas manifestações individuais que enfatizavam a subjetividade e a alteridade, oriundas principalmente das contribuições literárias de gays e feministas chicanos. Seja em sua origem coletivista ou em suas expressões de subjetividade, a Virgem de Guadalupe ocupa um importante papel simbólico neste movimento (Maurício de BRAGANÇA, 2006).

Com forte apelo cultural, a santa foi frequentemente atrelada a movimentos políticos ao longo da história mexicana, mas sua função simbólica nesses espaços tinha o propósito de evocar submissão, enquanto que no âmbito do chicanismo ela adquire um papel de resistência:

A iconografia guadalupana que tradicionalmente no México fora construída como um ponto de articulação da recusa à modernidade e à mudança, promovendo a submissão social e a passividade política (numa engenhosa vinculação entre o nacional e o popular que se iniciara com a Revolução de 1910 e se substanciaria com o desenvolvimento da indústria cultural capaz de disseminar o projeto político em torno da construção dos signos de mexicanidade), ganha novos matizes no discurso político chicano. Para os mexicanos-americanos, isso é bastante diferente. $O$ que no México estava vinculado à opressão e ao autoritarismo, produzindo artificiais signos de mexicanidade, na Califórnia representava um local de resistência e contestação à cultura anglo-americana (Maurício de BRAGANÇA, 2006, p. 2-3).

No contexto chicano a Virgem de Guadalupe passa a ser vista como uma guerreira protetora de seus ativistas, mas para as chicanas feministas, sua releitura ganha outros contornos. Para elas, o mito de Coatlicue narrado por Sahagún tem outro significado, em que a morte de Coyolxauhqui, resultante da traição de seu irmão, representa o momento de transição de uma sociedade ginocêntrica para uma androcêntrica e Coyolxauhqui se torna a divindade Lua (Irene LARA, 2005). Não é por 
acaso, portanto, que a releitura arquetípica da mitologia de Guadalupe figure frequentemente na prática chicana feminista até os dias atuais.

Nos parágrafos seguintes, apresentaremos algumas das ressignificações chicanas da Virgem de Guadalupe, a começar pela releitura realizada por uma das precursoras do movimento feminista chicano, Gloria Anzaldúa. Nossa intenção não é dar conta de apresentar todas as novas imagens chicanas de Guadalupe, uma vez que a própria metodologia adotada neste processo não permite isso. Nosso propósito com esta revisão da literatura acadêmica existente sobre as releituras do mito de Guadalupe é demonstrar seu alcance e amplitude. Inicialmente na literatura, estas apropriações femininas da mitologia transitam pelas artes plásticas, cinema, pedagogia, ecoando até na saúde, através da prática psicoterapêutica.

\section{ELA ME LEMBRAVA DE QUE EU ERA, DE FATO, SAGRADA 15}

Guadalupe foi uma figura central na vida de Gloria Anzaldúa, assim como na de muitos chicanos que viam nela a possibilidade de resgatar sua cultura indígena, como demonstra a sua descrição da Virgem:

Atualmente, La Virgen de Guadalupe é a mais potente imagem religiosa, política e cultural de chicanos/mexicanos. Ela, como minha raça, é a síntese do velho e do novo mundo, da religião e cultura de duas raças em nossa psique, os conquistadores e os conquistados. Ela é o símbolo do mestizo fiel aos seus valores indígenas. La cultura chicana se identifica com a mãe (indígena) em vez do pai (espanhol). Nossa fé está enraizada nos atributos, imagens, símbolos, magia e mitos indígenas. Porque Guadalupe tomou para si a devastação física e psicológica dos índios conquistados e oprimidos, ela é nosso símbolo espiritual, político e psicológico. Enquanto um símbolo de esperança e fé, ela sustenta e assegura nossa sobrevivência. O índio, apesar do extremo desespero, sofrimento e quase genocídio, sobreviveu. Para mexicanos dos dois lados da fronteira, Guadalupe é o símbolo de nossa rebelião contra os ricos e as classes médias e altas, contra

15 She reminded me that indeed I was sacred and deserved to be in this place of privilege / "Ela me lembrava de que eu era, de fato, sagrada e que merecia estar nesse lugar de privilégio" (Irene LARA, 2008, p. 65, tradução livre). 
sua subjugação do pobre e do indígena ${ }^{16}$ (Gloria ANZALDÚA, 1987, p. 30, tradução nossa).

Para Anzaldúa, nascida no Texas em 1942, ser uma chicana feminista trazia um olhar ainda mais profundo à Guadalupe, pois para ela, seu resgate significava recuperar partes, negadas a todas as mulheres chicanas, que lhe foram extirpadas tanto pelos espanhóis como pelos astecas:

Depois da conquista, os espanhóis e sua igreja continuaram a repartir Tonantsi/Guadalupe. Eles dessexualizaram Guadalupe, removendo Coatlalopeuh, a serpente/sexualidade. Eles finalizaram a separação iniciada pelos Nahuas ao transformarem a La Virgen de Guadalupe/ Virgen María em virgens castas e Tlazolteoltl /Coatlicue /La Chingada em putas; nas Belas e nas Feras. Eles foram ainda mais longe; eles transformaram em trabalho do diabo todas as divindades indígenas e suas práticas religiosas ${ }^{17}$ (Gloria ANZALDÚA, 1987, p. 27-28, tradução nossa).

Os aspectos conservados e renegados de Tonantsi ${ }^{18} /$ Guadalupe carregam em si os simbolismos daquilo que os conquistadores queriam que fosse mantido. De Guadalupe, a docilidade, sinônimo de submissão, deveria ser preservada; de La Chingada, o sentimento de vergonha das

16 Today, La Virgen de Guadalupe is the single most potente religious, political and cultural image of the Chicano/mexicano. She, like my race, is a synthesis of the old world and the new, of the religion and culture of the two races in our psyche, the conquerors and the conquered. She is the symbol oh the mestizo true to his or her Indian values. La cultura chicana identifies with the Mother (Indian) rather than the Father (Spanish). Our Faith is rooted in indigenous atributes, images, symbols, magic and myth. Because Guadalupe took upon herself the psychological and physical devastation of the conquered and oppressed indio, she is our spiritual, political and psychological symbol. As a symbol of hope and Faith, she sustains and insures our survival. The Indian, despite extreme despair, suffering and near genocide, has survived. To Mexicans on both sides of the border, Guadalupe is the symbol of our rebelllion against the rich, upper and middleclass; against their subjugation of the poor and the indio (Gloria ANZALDÚA, 1987, p. 30).

17 After the Conquest, the Spaniards and their Church continued to split Tonantsi/Guadalupe. They desexed Guadalupe, taking Coatlalopeuh, the serpente/sexuality, out of her. They completed the split begun by the Nahuas by making La Virgen de Guadalupe/Virgen María into chaste virgins and Tlazolteot/Coatlicue/La Chingada into putas; into the Beauties and the Beasts. They went even further; they made all Indian deities and religious practices the work of the devil.

18 Conservamos aqui a grafia adotada por Anzaldúa para o nome da divindade. 
raízes indígenas deveria permanecer e de La Llorona $^{19}$, a auto imagem de um povo martirizado é que se mantinha (ANZALDÚA, 1987). Nesse sentido, o resgate do aspecto de Coatlicue - a deusa serpente - tem destaque em um dos mais famosos livros de Gloria Anzaldúa: Borderlands/La frontera (1987).

Nesta obra, ela aborda a estigmatização dos arquétipos de Tlazolteoltl/Coatlicue/La Chingada e seu efeito para a psique das mulheres chicanas, assim como o não-pertencimento tipicamente experimentado por habitantes das zonas de fronteira e o sofrimento psíquico derivado desse não-lugar. Para ela, o caminho para uma nova consciência, a consciência mestiça, passa pela superação da dicotomia virgem/puta através da reintegração dos aspectos de Coatlalopeuh-Coatlicue à Guadalupe, enquanto deusa/divindade Mãe. Ela ressalta, no entanto, que este não é um trabalho isolado e que, para tanto, as chicanas devem apoiar-se umas às outras neste processo de transformação dos fundamentos sexistas da cultura chicana, já que para ela "a luta da chicana é acima de tudo, uma luta feminista”20 (Gloria ANZALDÚA, 1987, p. 84, tradução nossa). O resgate almejado por Anzaldúa foi realizado por inúmeras chicanas feministas e se estende até os dias atuais e Patricia Nelson (2008) debruçou-se sobre o processo de ressignificação de Guadalupe realizado na literatura acadêmica e não-acadêmica por algumas destas chicanas: Sandra Cisneros, Cherríe Moraga e Ana Castillo.

De acordo com Nelson (2008), Cisneros produziu releituras de La Llorona e da Virgem de Guadalupe em suas obras Guadalupe the Sex Goddess (1996) e Woman Hollering Creek (1991). Nelas, deu voz à La Llorona, que, para ela, sempre foi sentenciada de forma unilateral, buscou recuperar, assim, a sexualidade e a liberdade de Guadalupe, tornando mais possível a identificação entre realidade das mulheres chicanas com a Virgem. La Llorona também foi relida por Cherríe Moraga em The Hungry Woman (2001) no contexto da crítica ao patriarcado e através dela, teceu críticas

19 La Llorona se refere a um mito mexicano de origens indígenas ainda não bem definidas e de muitas variações. Trata-se da história de uma mulher que, traída por seu marido, afoga seus filhos em um rio. Sua punição é andarilhar eternamente por toda a Terra em busca de seus filhos, assombrando riachos e córregos com seu choro e lamento de dor. Algumas teorias da origem do mito de La Llorona a remetem à Cihuacoatl pré-asteca.

20 The struggle of the mestizaa is above all a feminist one. 
à estrutura normativa da família chicana e ao sexismo e heterossexismo do nacionalismo chicano. Já a produção So Far From God (1993) de Ana Castillo não redesenha um mito em específico, mas realiza uma análise da própria produção mitológica, em um processo que critica o papel exercido pela Igreja Católica na produção de ícones femininos idealizados.

Nas Artes Plásticas, são fartamente conhecidos os trabalhos de Yolanda López, Ester Hernández e Alma López. O mais famoso quadro de Yolanda López, Margaret F. Stewart: Our Lady of Guadalupe $e^{21}$, traz uma costureira chicana que simboliza a Virgem de Guadalupe produzindo o seu próprio manto e faz parte de uma série de retratos de representações de Guadalupe como uma mulher chicana comum (Irene LARA, 2008). O título desta seção do artigo - Ela me lembrava de que eu era, de fato, sagrada - é uma citação da fala de Irene Lara sobre o que sentiu quando esteve em frente ao quadro de Yolanda López, sendo, portanto, autoex-

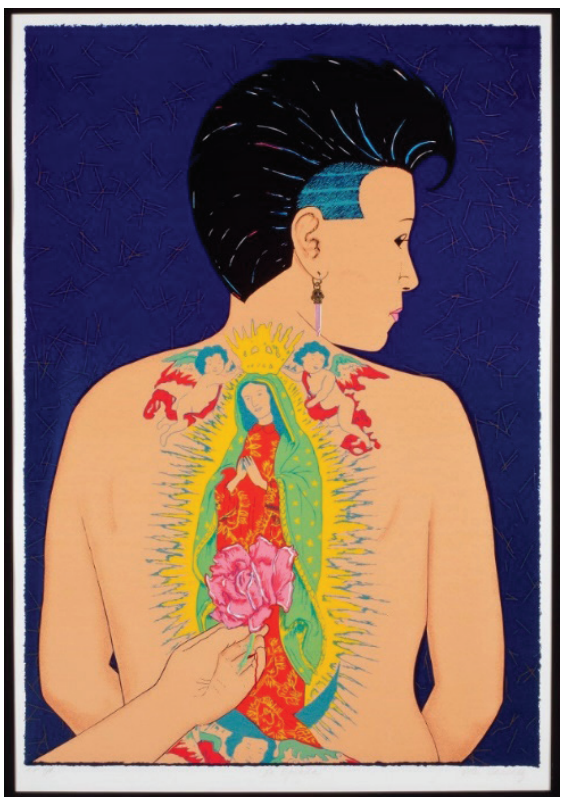

Figura 3: La Ofrenda (1988)

Ester Hernandez/National Museum of Mexican Art (Google Arts \& Culture) plicativo do efeito desta obra para estas mulheres.

Ester Hernández, por sua vez, produziu em 1988 sua obra La Ofrenda, que retrata Tonantzin-Guadalupe tatuada nas costas nuas de uma mulher chicana, recebendo - Guadalupe e/ou a chicana - a oferta de uma rosa. Novamente, a heteronormatividade é questionada nesta obra, que desvencilha a nudez feminina da objetificação (Irene LARA, 2008). Outra López que produziu releituras de Guadalupe nas Artes Plásticas foi Alma López. Para Guisela Latorre (2008), seu trabalho

${ }^{21}$ Disponível em: http://almalopez.com/projects/ChicanasLatinas/lopezyolanda3.html 
descentraliza a ideia de poder da figura masculina, a forma como é tradicionalmente encontrada nos movimentos nacionalistas mexicanos. O produto dessa descentralização é o protagonismo de mulheres chicanas nos discursos de emancipação e descolonização. Seu trabalho se desenvolve fortemente na esfera virtual e seu retrato digital chamado Our Lady (2001) recebeu reações violentas, que incluíram demandas de censura e ameaças de morte:

A imagem é composta por uma montagem digital da artista performática Raquel Salinas representando a Virgem de Guadalupe, que aqui volta seus olhos desafiantes para o espectador, algo muito distante dos olhos cabisbaixos de Guadalupe da iconografia tradicional. A Lady de López veste um biquini de rosas, sendo esta flor especificamente uma referência à associação com a Virgem Maria, e um manto azul que apresenta relevos das pedras da escultura de Coyolxauhqui, a deusa asteca da Lua. Esta Guadalupe moderna não é sustentada por um anjo, mas pela imagem de Raquel Gutiérrez ativista cultural e amiga pessoal da autora - com

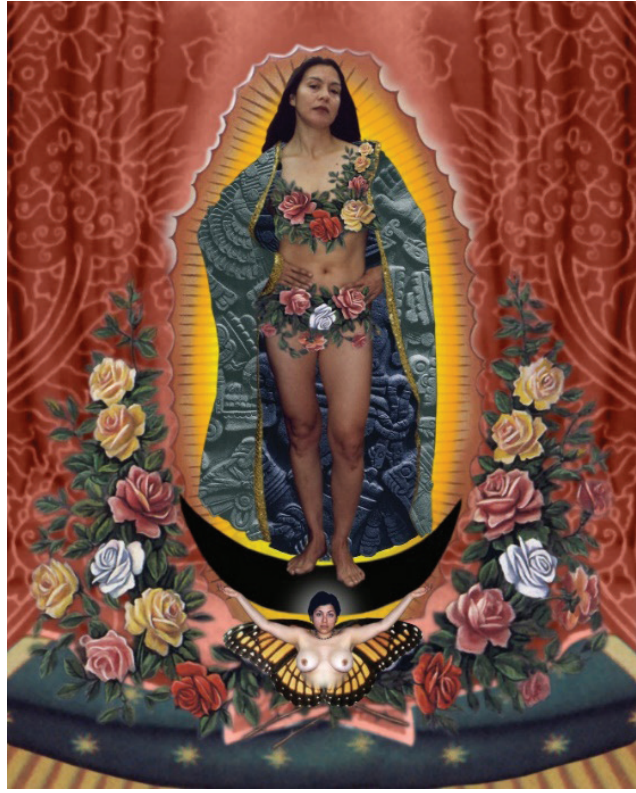

Figura 4: Our Lady

Alma López (2001)/www.almalopez.com os seios nus. Gutiérrez ostenta um par de asas de borboleta-monarca, uma iconografia particularmente significativa para López ${ }^{22}$ (Guisella LATORRE, 2008, p. 133, tradução nossa).

22 The image is composed of a digital montage depicting performance artist Raquel Salinas cast in the role of the Virgin of Guadalupe, who here defiantly returns her gaze eyes to the viewer, a far cry from the downturned eyes if the Guadalupe in traditional iconography. López Lady 
Guadalupe também foi relida em 2001 por Marion Martinez, que tece críticas aos conflitos socioculturais decorrentes da colonização e à mitificação da tecnologia através de sua escultura Oratorio a La Virgencita, produzida com sucata de hardwares (Eliane ÁVILA, 2015).

No Brasil, um projeto cinematográfico engendrado por Isadora Ebersol e Denise Bussoletti trabalha a partir da associação de Tonantsi-Guadalupe para discutir fronteiras na identidade de gênero, maternidade e as fronteiras entre ciência e arte (Isadora EBERSOL e Denise BUSSOLETTI, 2019).

Apesar de mais frequentes no âmbito das artes, as releituras de Guadalupe têm outros alcances. Amylia Barnett (2013), por exemplo, relata o meticuloso trabalho de análise da mitologia mexicana produzido por Alejandra Elenes em Transforming Borders: Chicana/o Popular Culture And Pedagogy (2011) - que passa, inclusive, pelas obras artísticas trazidas neste artigo - para a elaboração de uma pedagogia emancipadora chicana. Já no âmbito da psicoterapia, Lillian Comas-Díaz trabalha arquetipicamente a psique de mulheres latinas, que frequentemente encontram em Guadalupe a face feminina da divindade.

\section{CONCLUSÃO DE UMA HOMENAGEM}

A virgem de Guadalupe foi sendo configurada no Tepeyac na metade do século XVI, quando indígenas continuaram a ir ao teocalli de Tonantzin, que agora era uma ermida dedicada à virgem. Desde os anos setenta do século XX, na fronteira entre EUA e México, entre muitas outras fronteiras, as mulheres chicanas têm feito de Guadalupe um caminho de resistência e luta, diferente do modelo de submissão feminina que tem vigorado no México. Como assinalou Gloria Anzaldúa, as chicanas liberaram com suas lutas a presença de Coatlicute, A da Saia de-Serpentes, princípio de criação e destruição, de vida e morte, que teria sido silenciado mesmo antes da chegada dos espanhóis. Através das

wears a rose bikini, a reference to the association of the Virgin Mary with this particular flower, and a blue mantle revealing the relief surface of the stone sculpture of Coyolxauhqui, the Aztec moon goddess. This modern-day Guadalupe is being held up not by an angel but rather by the figure of a bare-chested Raquel Gutiérrez, cultural activist and personal friend of the artist. Gutiérrez sports a pair of Monarch butterfly wings, an iconographic motif that is particularly significant to López [...] (Guisella LATORRE, 2008, p. 133) 
mulheres chicanas, Guadalupe/Coatlicute recupera sua condição de lugar de encontros entre diferentes, onde elaboram-se apropriações e ressignificações, representações estas do hibridismo constituinte da América: invenção da modernidade preenchida por ocultamentos. Finalizamos esta jornada chicana com o significado da Virgem de Guadalupe para Sara, uma das pacientes de Comas-Díaz: "Guadalupe me ama porque eu sou morena" (Lillian COMAS-DÍAZ, 2003, p. 150, tradução nossa)²3.

Colocamos na introdução do artigo que ele era um ensaio desafiador. $O$ entendemos assim primeiro, pela densidade do objeto que foi-se desenhando na parte da pesquisa. Definimos uma questão que terminou sendo enorme pois atravessa mitologias, arquétipos, invenções religiosas eruditas e populares, discursos e crenças, ressignificações de símbolos, lutas das mulheres chicanas e finalmente representações plásticas elaboradas sobre o ícone de Guadalupe, por artistas chicanas contemporâneas. Segundo, porque ele está atravessado por diferenças, dois pesquisadores com metodologias e objetos de pesquisa distintos; escrito por uma mulher e um homem, uma filósofa feminista defensora das rupturas e um historiador às voltas com o rigor acadêmico.

Chegamos no final acreditando que honramos nossa proposta e que valeu o desafio a que nos propusemos, mesmo com os perigos de desandar. Riscos como estes correm na vida das ativistas e dos acadêmic@s, em situações únicas como homenagear à intelectual e ativista Maria José Fontelas Rosado Nunes, que nunca renunciou a perguntar ou, com sua elegância discreta, discordar.

\section{REFERÊNCIAS}

ANZALDÚA, Gloria. Borderlands/La frontera: the new mestiza. San Francisco: Aunt Lute, 1987.

ANZALDÚA, Gloria. Viver nas fronteiras significa que você. Mandrágora, volume 16, n. 16, p. 113-114, 2010. Disponível em https://www.metodista.br/revistas/revistas-ims/index. php/MA/article/view/2049/2020. Acesso em 23 out 2020.

ÁVILA, Eliane de Souza. «Do high-tech à azteca»: descolonização cronoqueer na ciberarte chicana. Rev. Estudos Feministas, volume 23, n. 1, p. 191-206, jan-abr, 2015. Disponível em: https://www.scielo.br/scielo.php?script=sci_arttext\&pid=S0104-026X2015000100191. Acesso em: 12 jul. 2020.

23 Guadalupe loves me because I am morena. (Lillian COMAS-DÍAZ, 2003, p. 150). 
BRADING, David. La virgen de Guadalupe: Imagen y tradición. México: Taurus, 2002. BRAGANÇA, Maurício de. Sexo e raça na virgem mestiça: imagens guadalupanas e feminismo chicano. Caligrama (São Paulo. Online), volume 2, n. 2, 2006. DOI: https://doi. org/10.11606/issn.1808-0820.cali.2006.56754. Acesso em: 06 jun. 2020.

COMAS-DÍAZ, Lillian. The Black Madonna: The psychospiritual feminismo of Guadalupe, Kali and Monserrat. In: SILVERSTAIN, Louise; GOODRICH, Thelma Jean. Feminist Family Therapy: Empowerment in Social Context. American Psychological Association, 2003.

EBERSOL, Isadora e BUSSOLETTI, Denise. Guadalupe: por entre a imagem criadora e devaneio poético. In: SILVA, Marcia Alves da, ROSA, Graziela Rinaldi da (orgs). Pedagogias populares e epistemologias feministas latino-americanas. Curitiba: Brazil Publishing, 2019.

FERNANDEZ, Adela. Dioses Prehispánicos de México. México: Panorama, 2008.

LARA, Irene. A Daughter of Coatlicue: An Interview with Gloria Anzaldúa. In: KEATING, AnaLouise (org). Entremundos/Amongworlds. New York: Palgrave Macmilliam, 2005.

LARA, Irene. Tonanlupanisma: Re-Membering Tonantzin-Guadalupe in Chicana Visual Art. Aztlán: A Journal of Chicano Studies, volume 33, n. 2., p. 61-90, Fall, 2008. Disponível em: https://www.academia.edu/13448464/Tonanlupanisma_Re-membering_Tonantzin-Guadalupe_in_Chicana_Visual_Art?auto=download. Acesso em: 12 jul. 2020.

LATORRE, Guisella. Icons of Love and Devotion: Alma López's Art. Feminist Studies, volume 34, n. 1/2, p. 131-150, The Chicana Studies Issue, Spring - Summer, 2008. Disponível em: https://www.jstor.org/stable/20459185?read-now=1\&refreqid=excelsior\%3Adcb34442 7093d2c34687095858452072\&seq=3\#page_scan_tab_contents . Acesso em 12 jul. 2020. LEÓN-PORTILLA Miguel. Tonantzin Guadalupe. Pensamiento náhuatl y mensaje cristiano en el "Nican Mopohua". México: FCE, 2001.

NELSON, Patricia. Rewriting Myth: New Interpretations of La Malinche, La Llorona, and La Virgen de Guadalupe in Chicana Feminist Literature. $778 \mathrm{f}$. Undergraduate Honors Theses. William \& Mary University. Williamsburg, 2008. Disponível em: https://scholarworks.wm.edu/honorstheses/788. Acesso em: 28 jun. 2020.

O'GORMAN, Edmundo. Destierro de Sombras. Luz en el origen de la imagen y culto de Nuestra Señora de Guadalupe del Tepeyac. México: UNAM, 1991.

SAHAGÚN, Bernardino. Historia General de las Cosas de Nueva España. México: Editorial Porrúa S.A., 1989.

SANTOS, Eduardo Natalino dos. Deuses do México Indígena. São Paulo: Palas Athena, 2002. SUESS, Paulo, (org.). A Conquista Espiritual da América Espanhola. Petrópolis: Vozes, 1992.

Submetido em: 31-7-2020

Aceito em: 5-11-2020

Mandrágora, v.26, n. 2, 2020, p. 113-137 